\title{
Correspondence
}

Correspondents are asked to be brief.
Abortions under the N.H.S.

H. G. E. Arthure, F.R.c.o.G. . . . . . . . 617

Are Antidiabetic Drugs Dangerous?

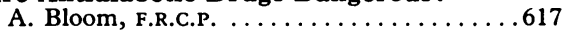

Early $X$ Rays

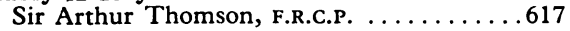

Analgesic Nephropathy

P. Kincaid-Smith, F.R.C.P.; U. C. Dubach,

M.D. ..................618

Health Services Financing

W. M. O. Moore, M.R.c.o.g. . . . . . . . . .619

Bell's Palsy and Surgery

L. B. W. Jongkees, M.D.
A. Griffiths, B.sc. ...............6619

Length of Gestation
Rational Oxygen Therapy

J. M. Leigh, F.F.A.R.C.S. .

Vasectomy

G. T. Watts, F.R.C.s. ; M. E. Humphrey, B.sc. 620

ibrinolytic Activity and Oral Contraception

Brucellosis in Veterinary Surgeons

D. G. McDevitt, M.D.; W. R. Thrower, M.D. 621

Hyperpyrexia after Anaesthesia

G. M. Hall, M.B. . . . . . . . . . . . .622

Angina and Indomethacin

D. N. Golding, F.R.C.P.I. . . . . . . . . . 622

Cardiff Infant In.

W. W. Mushin, F.F.A.R.C.S., and E. K

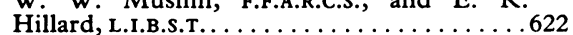
I. S. Menon, M.B., and Mary Peberdy, M.R.C.s.....................621
Emphysema in Coalworkers

R. C. Ryder, M.R.C.PATH., and others. . . . 623

Shortage of Technicians

I. J. Y. Cook, F.I.M.L.T. . . . . . . . . . .623

Virus-like Structures in Lupus Erythema-

tosus

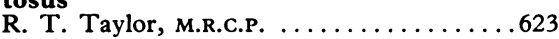

Rickards Memorial Fund

W. I. C. Morris, F.R.C.o.G., and others . ...623

M. K. Strelling, M.R.C.P. . . . . . . . . .6624

J. M. Childs, M:B. . . . . . . . . . . . . 624

Medical Man

Medical Manpower
D. C. Kilbride, M.B.
Comparative Career Earnings

Reports of Coroners' P.M.s

\section{Abortions under the N.H.S.}

SIR,-The Abortion Act (1967) states that "in determining whether the continuance of a pregnancy would involve such risk of injury to health ... account may be taken of the pregnant woman's actual and reasonably foreseeable environment."

I am frequently faced with two socioeconomic problems. Firstly, the married woman with poor living conditions, inadequate for her present family, let alone an additional child. It may be that she and her bed with one or more children, with a cot for the youngest. Ablutions may take place in the kitchen, or in a communal washhouse. Not infrequently the woman goes to work, either because her husband is missing or does not provide sufficient money.

Secondly, a single girl, ignorant or careless about contraception, and frightened to tell her parents of her predicament. The putative father no longer seems to take any responsibility, and she cannot face the consequences of pregnancy, which entail either giving up her job or her training.

It seems to me that social services do remarkably little for either the unmarried girl or the married women with poor housing conditions, even if they could be persuaded to continue with their pregnancy. It is not surprising that they suffer from a reactive depression, and I believe that abortion should be available to them on the National Health Service. It is speedily availhusband live in one room, sharing a double able in the private sector for those who can afford or can borrow the money. Unfortunately the waiting list for outpatient appointments is increasing, and there may be unavoidable delay in admission to hospital. According to the Annual Report of the Chief Medical Officer of Health for $1969^{1}$ the number of patients on gynaecological waiting lists has increased considerably.

The mortality from legal abortion before 12 weeks may be lower than maternal mortality excluding abortion, but the risks of abortion increase after 12 weeks, and altogether in 1969 there were 18 deaths associated with over 54,000 pregnancies terminated.

The increasing number of notified abortions can be controlled only by improved sex education and freely available contraception, but this will take time. There is an urgent need for additional outpatient facilities, and either an increase in beds, preferably separated from other gynaecological patients, or a better use of the existing beds. For this we need an increase in staff, workers.-I am, etc.

London, W.1.

\section{H. G. E. ARTHURE.}

\section{REFERENCE}

Department of Health and Social Security. On the State of the Public Health: Annual Report of the Chief Medic medical, nursing, and medical social

tolbutamide reduces the risks of cardiovascular disease.

The dose of tolbutamide (1.5 g. daily) was a high one, and, judged by the good diabetic control obtained in the placebo group, seems in any event to have been administered unnecessarily. All patients in this trial could have been controlled on dietary restriction without recourse to tablets or insulin. If this is not so the groups are not comparable.

There is no available evidence that the biguanides are associated with an increased mortality from cardiovascular disease. The mode of action of the biguanides is entirely different from that of the sulphonylureas. It is illogical to make recommendations for the use of both types of drugs on evidence obtained from tolbutamide alone.

The mortality rate from cardiovascular disease was slightly higher (though not significantly so) in the two groups treated with insulin than in the placebo group. Where is the logic for recommending insulin in this type of patient?

Even if the findings of the American multicentre trial are accepted the most that can be deduced is that long-term treatment with high dosage tolbutamide is unwise in subjects who can be adequately controlled by diet alone.-I am, etc.

London W.1.

ARNold Bloom.

\section{Early $X$ Rays}

\section{Are Antidiabetic Drugs Dangerous?}

SIR,-I would like to associate myself with the attitude adopted in your leading article on this subject (21 November, $p$. 444). Basing its view on the findings of a multicentre trial, the American Diabetic Association recommends that insulin should be used where possible in mild maturityonset diabetics not responding to diet or weight loss. Even if one accepts the validity of the findings that tolbutamide was

SIR,-Dr. E. Posner's interesting account of the "Reception of Röntgen's Discovery in Britain and the U.S.A." (7 November, p. 357) omits any reference to a paper ${ }^{1}$ in which my late colleague J. F. Brailsford stated categorically that the first clinical application of $x$ rays was made in Birmingham by two general practitionersJ. R. Ratcliffe and J. Hall Edwards. Ratcliffe's account of what happened in January 1896 is as follows.

"We met in Baynton's photographic shop associated with a significantly higher death rate from cardiovascular disease (and there are several compelling reasons for doubting this validity) the advice offered by the American Diabetic Association is illogical.

The results of the trial showed no difference in mortality between any of the groups during the first five years. As your leading article points out, there is evidence from other sources that within five years 
and discussed the news. Hall Edwards obtained a Crooke's tube and I fortunately had a patient who made the largest induction coils in the Midlands and borrowed one. After evening surgery we set up the apparatus and made some experiments. We found that we could see the outlines of the bones of the hand and it suddenly struck us that the rays might be useful in the removal of foreign bodies. I then pushed a hyporlermic needle into my hand and saw that its outline was very sharply demarcated by the rays. We telephoned the hospitals and asked them to send us a patient with a foreign body in the hand to see if the photograph would be of any use to the surgeon who had to remove it."

The next day Dr. J. Hazlewood Clayton, a part-time casualty surgeon at the Queen's Hospital, sent them a woman who said that she had run a needle into her hand a few days previously and that it was painful although there was no clinical evidence of it. The "shadowgraph," as they called it, showed the needle clearly and Dr. Clayton took it out. The note he made of the operation was found among his papers after his death and was presented to the Barnes Library of the Birmingham Medical School by his daughter Mrs. Wilson.

The fact that when young I knew the three busy men concerned in this adventure stimulated me to write this note in their memory.-I am, etc.,

\section{A. P. Thomson.}

Edgbaston, Birmingham.

REFERENCE

1 Brailsford, J. F., British fournal of Radiology,

\section{Analgesic Nephropathy}

SIR,-Thank you for heading your leading article (17 October, p. 125) "Analgesic Nephropathy" and not "Phenacetin Nephropathy." I very much regret the return to the term phenacetin nephropathy. The view expressed by Dr. K. G. Koutsaimanis and Professor H. E. de Wardener (17 October, p. 131) that phenacetin is the cause of analgesic nephropathy and the reasons which they give have been repeated many times over the past 20 years. They are the views which I held soon after I came to Australia twelve years ago and recognized a new form of papillary necrosis which appeared on the necropsy table once or twice a week, whereas I had failed to recognize it over a six-year period at $\mathrm{Ham}$ mersmith Hospital, although I performed many necropsies and attended almost all.

The distressingly high incidence of this disorder in Australia, together with our evidence $^{1-3}$ that almost all patients recover but that withdrawal of phenacetin alone does not stop progression, makes it very important that doctors should realize the potential nephrotoxicity of other ingredients of analgesic mixtures such as aspirin, paracetamol, amidopyrine, and phenazone. One or more of these substances, all of which have been shown to be nephrotoxic, is present with phenacetin in all recorded cases of so-called phenacetin nephropathy of which I am aware.

Let us by all means put phenacetin at the top of the black list of potentially dangerous analgesics in man. Experience in animals suggests that phenacetin and paracetamol may be the least hazardous, but as you rightly point out (17 October, p. 125) experimental evidence may not be applicable to man. I doubt whether the Dunlop Committee, the F.D.A., or any similar body would give their blessing to a substance which produces papillary necrosis in animals. However, animal toxicity studies have let us down in the past and will let us down in the future.

Let us restrict our interest to one facet of this problem. How can we best prevent renal failure due to analgesic nephropathy in man? Experience in Australia has shown that this cannot be done by banning phenacetin alone. Widespread publicity about the dangers of phenacetin eight years ago and its removal from National Health Service listing led almost all pharmaceutical companies to substitute paracetamol for phenacetin in their A.P.C. mixtures. Analgesic nephropathy is still very common. ${ }^{3}$ An official decision that phenacetin was the cause of analgesic nephropathy appeared to increase the incidence of analgesic nephropathy within our own unit. Several patients whom we had persuaded months or years before to stop taking analgesics started taking mixtures which contained no phenacetin, having been assured by doctors, chemists, or advertisements that these were now safe. Such patients, who had had stable renal function, suffered severe relapses of typical uraemic papillary necrosis shortly after they had returned to taking large quantities of non-phenacetin analgesics. The detailed documentation in these patients is in press. ${ }^{2} 3$

Linked with this observation that renal function may deteriorate abruptly as a result of taking analgesics which did not contain phenacetin is the important evidence that in our experience ${ }^{1-3}$ severe renal failure due to analgesic nephropathy has invariably been recovered from. In your leader you quote the $17 \%$ incidence of analgesic nephropathy in a series of 175 renal transplants carried out in various hospitals in Sydney. Experience in our own hospital in Melbourne contrasts strikingly with that in Sydney in that not one of 110 patients admitted to our maintenance dialysis and transplantation programme has had analgesic nephropathy. No patient with analgesic nephropathy has been rejected. Some have been considered for transplantation when they were in severe renal failure on temporary dialysis but in these function has recovered..$^{1-3}$ It is possible that this invariable recovery from severe renal failure which we have observed in a review of 52 patients over six years is at least in part due to our scrupulous care to withdraw all potentially hazardous analgesics. Not only do we insist upon withdrawal of aspirin, paracetamol, phenacetin, and caffeine but we also withdraw any other agent which has been shown to produce papillary necrosis in animals. Phenylbutazone and flufenamic and mefenamic acid share this property with amidopyrine and salicylates. We also withdraw such agents as propoxyphene and indomethacin although we have no definite evidence against these.

We are always relieved to find that analgesic nephropathy is the underlying cause in a patient with severe renal failure because we now confidently anticipate recovery of renal function in this group. This attitude is clearly nut shared by our colleagues in Sydney, nol by Professor David Kerr, who writes as though transplantation is inevitable in a man of 56 who has a creatinine clearance of $14 \mathrm{ml}$. per minute (7 Novembe1, p. 364).

Finally Dr. Koutsaimanis and Professor de Wardener say that had phenacetin been suspected of causing renal papillary carcinoma it would have been prohibited some years ago. This is unfortunately not the case. Hultengren ${ }^{5}$ reported the association between renal papillary necrosis and renal pelvic carcinoma five years ago, and Bengtsson in several papers since her original one in $1968^{6}$ has suggested that this is due to phenacetin. Whether it causes carcinoma or not we certainly agree with Dr. Koutsaimanis and Professor de Wardener that phenacetin and paracetamol should be available only on a doctor's prescription, but would also like to see this restriction applied to aspirin and the other drugs which we mention. We have discovered through bitter experience over the past eight years that the danger of restricting only phenacetin lies in the implication that other freely available minor analgesics are safe. Until we know with certainty which ingredients of "over the counter" analgesics cause papillary necrosis in man surely it is better to be safe than sorry.-I am, etc.,

\section{Priscilla Kincaid-Smith.}

\section{Royal Melbourne Hospital,} Victoria, Australia.

\section{REFERENCES}

Nanra, R. S., Fairley, K. F., and Kincaid-Smith, P., Australasian Annals of Medicine, 1970, 19, 19

Kincaid-Smith. P. Nanra, R. S., and Fairley, K. F., in Renal Infection and Renal Scarring, press. Kincaid-Smith.iand K. F. Fairley. In $P$. In press.

incaid-Smith. Pedical fournal of Australia, $1969,2,1131$.

Hultengren, N. Lagergren, C., and Liungovist. A.. Acta Chirurgica Scandinavica, 1965, 130 , Bengtsson. U.. Angervall, L.. Ekman. H., and Lehmann, L., Scandinavian four

SIR, - I have read your leading article (17 October, p. 125) and the paper by Dr. K. G. Koutsaimanis and Professor H. E. de Wardener (17 October, p. 131) with great interest. It is astonishing to learn that analgesic nephropathy, a very well-known clinical entity in central and northern Europe, has at last become acceptable in the United Kingdom. Numerous papers have appeared in central Europe since 1953, when Spühler and Zollinger ${ }^{1}$ first described a type of nephropathy found at necropsy in some patients regularly taking analgesics containing phenacetin. The geographical distribution of the disease has been such that in English-speaking areas of the world new cases have only rarely been reported, except in Australia. ${ }^{2}$ It seems important, therefore, that for epidemiological and geographical evaluation use should be made of the possibility of detecting $\mathrm{N}$-acetyl-paminophenol, the main metabolite of phenacetin, in the urine. History-taking alone is insufficient for reaching a diagnosis of abuse of analgesics, and to wait for papillary necrosis to occur seems 